\title{
COMENTARIOS DE SENTENCIAS CONSTITUCIONALES DE ADMINISTRACION LOCAL
}

\author{
POR \\ Javier Montero y Casado de AMEzCua
}

\begin{abstract}
MAYOR OBJETIVACION DE LOS MERITOS EN EL SISTEMA VIGENTE DE CONCURSOS PARA CUBRIR VACANTES DE SECRETARIOS DE ADMINISTRACION LOCAL
\end{abstract}

El Tribunal Constitucional, en sentencia 193/1987, de 9 de diciembre, dictada en recurso de amparo interpuesto contra Orden del Ministerio de Administración Territorial que otorgó nombramiento de Secretario de Administración local, ha sentado una importante doctrina sobre el principio de igualdad en su relación recíproca con las de mérito y capacidad, todo ello relativo al acceso a funciones y cargos públicos.

El recurso de amparo fue planteado por un Secretario de Administración local de primera categoría que, pese a haber ocupado el primer lugar en la terna de los funcionarios con mayor puntuación solicitantes de la vacante, no fue nombrado por el Ministerio de Administración Territorial, al aceptar éste la propuesta de la Corporación, la cual eligió al funcionario que ocupaba el tercer lugar.

EI Alto Tribunal, con ocasión de resolver este recurso, realiza importantes precisiones sobre diferentes puntos de interés que se exponen a continuación:

1. La impugnación de las bases del concurso como requisito previo para recurrir su resolución

Es este un criterio tradicionalmente sostenido por la jurisprudencia y que se apoya, en último término, en el principio venire contra factum proprium y en las exigencias de la seguridad jurídica, lo que obliga -según ha venido siendo entendido- a que quien quiera discutir los resultados de un concurso sobre la base de ilegitimidad de las bases, ha de impugnar éstas previamente, pues, de lo contrario, existiría un acto propio de aceptación de las mismas bases que le impide la posterior impugnación del resultado.

El Tribunal Constitucional, a este respecto, lleva a cabo una serie de precisiones que tienen como presupuesto de hecho la circunstancia de estar resolviendo un recurso de amparo. Desde este 
punto de vista, el Alto Tribunal rechaza la pretendida inadmisibilidad del recurso alegada implícitamente por el Letrado del Estado, y señala que aunque es cierto que la presunta lesión de los derechos fundamentales invocados tiene su causa remota en las bases del concurso, no lo es menos que la lesión sólo pudo haberse producido, de manera efectiva, a través de la Orden ministerial impugnada que nombró Secretario del Ayuntamiento a persona distinta del solicitante. Dado que - precisa el Tribunal- en el proceso de amparo no se lleva a cabo un enjuiciamiento abstracto de las normas, sino que tiene como finalidad específica el restablecimiento o reparación de las lesiones concretas causadas por actos de los poderes públicos en la esfera de los derechos fundamentales y de las libertades públicas de los ciudadanos, es obvio que sólo a través de un acto como la Orden aquí impugnada pudo menoscabarse la esfera citada, ya que, aun suponiendo que las bases y las normas en las que se apoyan fueran inconstitucionales, si el nombramiento de Secretario del Ayuntamiento de León hubiera recaído en el ahora solicitante de amparo, no habría lugar a plantearse la reparación de los derechos presuntamente vulnerados.

\section{El régimen especial de los concursos de traslados y la autonomía municipal.}

Tras llevar a cabo algunas funciones sobre el carácter propio del recurso de amparo, en el sentido de insistir en su carácter subjetivo como vía de protección de derechos y libertades procediendo el examen de la constitucionalidad de las disposiciones generales aquí sólo en cuanto "prius" para determinar si ha habido efectivamente violación de derechos protegidos en esta vía, el Tribunal Constitucional se adentra propiamente en el núcleo del problema planteado en las alegaciones de la Corporación la cual considera que el sistema de valoración no tasado coordinado con otro de puntuación objetiva constituye una manifestación mínima de la autonomía municipal inocua a los fines del recurso de amparo. Frente a esta afirmación, el demandante de amparo entiende que los preceptos en que se establece el régimen especial de los concursos son inconstitucionales al violar el principio de igualdad.

El Tribunal Constitucional en relación con este punto disecciona sugerentemente el problema y advierte que el sistema normativo aludido, según el cual la Corporación Local tiene la facultad de establecer, mediante una terna, el orden de preferencia con vistas al nombramiento por parte del Ministerio de un funcionario perteneciente a uno de los Cuerpos Nacionales de Administración local 
(preferencia que no tiene por qué seguir el orden de puntuación otorgado objetivamente de acuerdo con el baremo de méritos previamente establecido antes de la correspondiente convocatoria), no guarda relación con el principio constitucionalmente reconocido de la autonomía municipal.

A renglón seguido el Tribunal corrobora el criterio, señalando que la autonomía local consiste, fundamentalmente, en la capacidad de decidir libremente, entre varias opciones legalmente posibles, de acuerdo con un criterio de naturaleza esencialmente política (STC núm. 4/1981, fundamento jurídico $3 .^{\circ}$ ), mientras que la resolución de un concurso de méritos para cubrir una plaza vacante de funcionarios ha de hacerse de acuerdo con un criterio estrictamente técnico, valorando exclusivamente el mérito y la capacidad del aspirante a la plaza de que se trate, conforme establece el artículo 103.3 de la Constitución. Criterio o juicio de naturaleza política en su caso, técnica en otros, opuestos entre sí, y emitidos, por lo demás, por órganos de carácter también diferente: un Ente o Corporación local en el primer caso, una Comisión o Tribunal, en el segundo.

El sistema vigente, arguye el Tribunal, lo único que permite a la Corporación local es establecer con carácter previo a la convocatoria del concurso un baremo de méritos específicos, en un porcentaje ciertamente importante (el 25 por 100 del total), pero que no corresponde aplicar a la propia Corporación, en cuanto tal, sino al Tribunal o Comisión que ha de resolver, en cada caso, el oportuno concurso. Con lo que, como es obvio, es a un órgano que emite valoraciones o juicios estrictamente técnicos, al que corresponde aplicar, respecto de cada candidato o aspirante a cubrir la plaza de que se trate, el baremo previamente establecido con carácter general. Bien entendido, además, que es al citado Tribunal al que compete no sólo evaluar los méritos de los candidatos, sino también formular la propuesta de nombramiento al Ministerio, que procederá a realizarlo en favor del candidato con mejor calificación.

Hay, pues, en el sistema vigente una mayor objetivación de los méritos, en la medida en que éstos se cuantifican a priori y con carácter general, encomendándose a un órgano distinto de la Corporación local que los ha establecido su aplicación en el caso concreto tras la oportuna convocatoria.

En conclusión, el Tribunal Constitucional entiende que la Orden Ministerial vulneró el derecho del ahora solicitante de amparo a acceder en condiciones de igualdad a las funciones y cargos públicos, consagrado en el artículo 23.2 de la Constitución, en la medida en que permitió a la Corporación local -como así ocurrióalterar, a su voluntad, el criterio establecido objetivamente de 
acuerdo con el baremo de méritos fijado con carácter previo y general.

\section{La relación recíproca entre el principio de igualdad y los de mérito y capacidad.}

En apoyo de la conclusión mantenida a lo largo de la sentencia, hace jugar al Tribunal por último la virtualidad de los principios constitucionales de igualdad, mérito y capacidad y con apoyo en otras sentencias, reafirma una importante doctrina entorno a la interpretación del artículo 23.2 de la Constitución, concluyendo que dicho precepto uimpone la obligación de no exigir para el acceso a la función pública requisito o condición alguna que no sea referible a los indicados conceptos de mérito y capacidad, de manera que pudieran considerarse también violatorios del principio de igualdad todos aquéllos que, sin esa referencia, establezcan una desigualdad entre españoles» (STC 50/1986). El artículo 23.2 introduce, así, un criterio igualatorio que constituye una garantía, reforzada por tratarse de un derecho fundamental, del principio de imparcialidad de los funcionarios públicos proclamado en el artículo 103.3, inherente por esencia al Estado de Derecho que la Constitución consagra. Por consiguiente, en la resolución de los procedimientos de selección para ocupar un puesto integrado en la función pública, los órganos y autoridades competentes deben guiarse exclusivamente por aquellos criterios de mérito y capacidad (STC $148 / 1986$, citada), incurriendo en infracción del mencionado precepto constitucional si tomaran en consideración otras condiciones personales o sociales de los candidatos, no referidos a dichos criterios. 